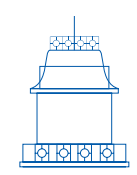

RESE N A

\title{
López Jiménez, C.A. (2018). El terreno común de la escritura: una historia de la producción filosófica en Colombia. Editorial Javeriana
}

\author{
Jorge Uribe-Vergara \\ Investigador independiente \\ Email: jorgeuribe7@hotmail.com | ORCID: 0000-0002-8080-0723 \\ https://doi.org/10.17533/udea.ef.347649
}

¿Qué es la práctica de escribir filosofía? El joven filósofo e historiador Carlos Arturo López Jiménez resuelve acertadamente esta respuesta en libro El terreno común de la escritura, al estudiar esta práctica entre 1892 y 1910 en Colombia, planteando como punto de partida, que "la escritura en filosofía, más allá de los intereses, compromisos o sucesos cotidianos, estuvo regida también por condiciones históricas relativas al ejercicio local de la escritura filosófica" (López Jiménez, 2018, p. 35).

El terreno común de la escritura es, por tal motivo, un libro que se suma a los estudios de la historia de la filosofía en Colombia, como el de Jaime Jaramillo Uribe, titulado El pensamiento colombiano en el siglo XIX; el de Álvaro Pablo Ortiz Rodríguez, Historia de la Facultad de Filosofía y Letras 1890-1930; los dos tomos editados por el Instituto Pensar, Pensamiento colombiano del siglo XIX; o la tesina de maestría en Historia de la Pontificia Universidad Javeriana -sede Bogotá- de Juan Manuel Dávila Dávila, Ciencias útiles y planes de estudio en la Nueva Granada. Pero, mientras que estos trabajos analizan las ideas y el marco histórico de la filosofía, la apuesta de López Jiménez se centra en las practicas de escribir filosofía en Colombia, entendidas como las maneras, más o menos reguladas de hacer, de pensar, etc.

Para hacer posible el análisis de las prácticas de escribir filosofía en Colombia, López Jiménez se adhiere a los estudios que señalan las herencias coloniales de la modernidad y la condición periférica de Colombia, y a aquellos que trazan la formación de sujetos modernos y su relación con la Iglesia Católica. Además, se distancia del concepto de modernidad que se utiliza en los análisis contemporáneos y revate la 
figura del intelectual y el campo de juego sociológico -entre otros conceptos-, que, desde la historia intelectual, se le ha querido dar a la historia de la filosofía colombiana, para proponer que:

quienes se encargaron de hacer las publicaciones tuvieron algún criterio de selección, y por más intereses que estuvieran en juego, por más conflictos que definieran su lugar en un campo intelectual concreto, hubo mínimos que debían cumplir: referencias a ciertos autores, uso incipiente o no de un aparato crítico, calidad gramatical, estructra lógica, temas que resultaba relevantes, etc. (López Jiménez, 2018, p. 90).

Con lo anterior, al apartarse de conceptos como el de intelectual y campo sociológico, El terreno común de la escritura presenta el concepto de escritores de filosofía. Este concepto se refiere a aquellos hombres que, además de redactar textos de diferente género, ocuparon cargos políticos, burocráticos, diplomáticos y académicos en algún momento de sus vidas, y que inicidieron en la filosofía. Sin embargo, es en este punto en el cual el lector se preguntará cómo ha sido escribir filosofía en Colombia entre 1892 y 1910; para dar respuesta a este interrogante, López Jiménez estudia, inspirado en el libro Las palabras y las cosas del filósofo francés Michel Foucault, las series escriturales de la filosofía. Series que otorgan una novedad metodológica sustancial al trabajo, en tanto apuesta arqueológica del saber y las disciplinas en Colombia.

La primera serie que analiza López Jiménez es la social, entendida como la comunicación entre pares y la divulgación del conocimiento especializado, demostrando que la filosofía, además de alojarse en las escuelas y universidades, también formó a una opinión pública, avida de conocer el pensamiento occidental europeo y sus exponentes; en la segunda, la material, explora la difusión de las revistas, los manuales de enseñanza de la filosofía del Colegio Mayor de Nuestra Señora del Rosario, así como los textos de sus estudiantes, comprobando la existencia de una actividad filosofíca previa a su normalización; y en la ultima, la técnica, muestra cómo los escritores de la filosofía colombiana del siglo XIX y principios del XX usaban un lenguaje analítico y profundo propio de la filosofía, antes de la fundación del Instituto de Filosofía de la Universidad Nacional de Colombia sede Bogotá en 1945.

Una muestra de la serie técnica es Carlos Arturo Torres y su libro redactado en 1909, Idola fori. Analizado en El terreno común de la escritura como un escritor que refutó el neotomismo institucionalizado y como un burocráta desligado de las animosidades bipartidistas coyunturales, este hombre, nacido en Santa Rosa de Viterbo, ocupó varios cargos en los gobiernos de turno -Liberal o Conservador-, en diferentes momentos de su vida. Por eso, Idola fori, y en general la propuesta filosófica de Torres, es una rareza filosófica y un punto de observación particular para la práctica de escribir filosofía en Colombia. 
Asimismo, el lector de El terreno común de la escritura encontrará la formación de los conceptos construidos por estos hombres, que se resumen en los siguientes: la idea liberal del Estado; el interés por el conocimiento científico y el progreso; Colombia plegada, como un objeto dado y no construido históricamente, al marco de referencia de la modernidad y punto de continuidad para un juicio sobre el presente del país y sus instituciones; $y$, finalmente, la posibilidad de escribir textos valiosos y con un criterio científico. El terreno común de la escritura, entonces, es una invitación a los historiadores y a los filosófos colombianos a desmarcarse de ver las ideas filosóficas del siglo XIX en Colombia como un mero efecto de los vaibenes políticos y sus pugnacidades mediaticas; y, en general, de aquellas construcciones narrativas que dudan de la existencia de una filosofía latinoamericana, deshistorizandóla de su pasado local.

Finalmente, la lectura de El terreno común de la escritura es pertinente y oportuna por tres razones. Primero, para la historia de las ideas en Colombia, ya que ofrece una interpretación razonada y sin ambajes de los filósofos y sus trabajos. Segundo, para leer de forma crítica los estudios que pretenden, de manera impostada, dividir la historia de la filosofía en dualidades políticas e intelectuales, entre aficionados y filósofos, escuelas y corrientes, etc. Tercero, el libro es una novedad metodológica por la forma en cómo rastrea las series y el relieve de la filosofía colombiana. Y, finlamente, más que remontarse a un pasado para descubrir el "origen" de la filosofía, la propuesta de López Jiménez subyase en el aporte metodólogico para abordar los textos filósóficos de aquellos escritores de la filosofía en Colombia, siendo una entrada a explorar la formación disciplinar de otros saberes sociales y humanistas.

\section{Referencias}

Dávila Dávila, J. M. (2012). Ciencias útiles y planes de estudio en la Nueva Granada: Método racional y canon wolffiano en la filosofía escolar neogranadina (1762-1862). Editorial Javeriana.

Jaramillo Uribe, J. (1964). El Pensamiento colombiano en el siglo XIX. Editorial Temis.

López Jiménez, C. A. (2018). El terreno común de la escritura. Una historia de la producción filosófica en Colombia 1892-1910. Editorial Javeriana. https://doi.org/10.11144/ Javeriana. 9789587813180

Ortiz Rodríguez, Á. P. (2003). Historia de la Facultad de Filosofía y Letras 1890-1930. Centro Editorial Universidad del Rosario. 